Sigmoidoscopy should be performed shortly after removal of a foreign body to look for mucosal tears, but in patients where the rectum has been habitually overdistended rectal damage is not found.

${ }^{1}$ Bailey, H, and Love, J McN, in A Short Textbook of Surgery, ed A J H Rains and H D Ritchie, 16th edn, p 1013. London, Lewis, 1975.

Royal Portsmouth Hospital, Portsmouth

T N D PEET, MB, FRCs, surgical registrar (present address: Hammersmith Hospital, London W12 OHS) combination of powerful antihypertensive therapy and intermittent haemodialysis. The unexpected remission of the subcutaneous manifestations is inexplicable. Possibly a spontaneous remission ${ }^{4}$ has taken place. Treatment with azathioprine or the low dosage of prednisolone was probably not responsible. Conceivably chronic uraemia suppresses fibroblastic function and thereby reduces excessive collagen formation.

Evidence suggests that haemodialysis or renal transplantation in systemic sclerosis associated with acute renal failure may partially reverse the progress of the disease and allow a more optimistic approach to management.

1 Moore, H C, and Sheehan, H L, Lancet, 1952, 1, 68.

2 Rodnan, G P, Schreiner, G E, and Black, R L, American fournal of Medicine, 1957, 23, 455.

3 Richardson, J A, Arthritis and Rheumatism, 1973, 16, 265.

4 Tuffanelli, D L, and Winkelmann, R K, Archives of Dermatology, 1961, 84, 359.

Department of Nephrology, Hull Royal Infirmary, Hull, North Humberside

D J BARKER, MB, MRCP, senior house officer

$M$ J FARR, MB, MRCP, consultant physician

\section{Resolution of cutaneous manifestations of systemic sclerosis after haemodialysis}

Acute renal failure, usually in association with accelerated hypertension, is a rare but well-described feature of systemic sclerosis. ${ }^{2}{ }^{2}$ It appears to develop relatively early in the disease, often without previous evidence of renal impairment, and carries a poor prognosis. Richardson ${ }^{3}$ has reported a patient in whom haemodialysis and renal transplantation resulted in survival for 18 months, and resolution of cutaneous manifestations, arthralgia and Raynaud's phenomena. We report here a patient in whom dialysis and hypotensive therapy have been instituted for 13 months.

\section{Case report}

A 42-year-old woman presented to Dr K Keczkes in the dermatology department in July 1974. She had noticed tenderness, pain, and stiffness in the fingers of both hands for the previous 18 months; later she had developed Raynaud's phenomena and extensive thickening with tightness of the skin around her face, lips, and neck. She also had had considerable difficulty in opening her mouth. There was no family history of systemic sclerosis, although a sister had had vitiligo, both parents pernicious anaemia and her mother rheumatoid arthritis.

She had waxy, yellowish, shiny thickening of the skin and subcutaneous tissues of her face, neck, hands, and around her mouth. She could not open her mouth more than $2 \mathrm{~cm}$ between the incisor teeth. There was considerable immobility of her fingers and she could not form a fist with either hand. The appearances were those of classical scleroderma. Her blood pressure was $150 / 100 \mathrm{~mm} \mathrm{Hg}$, but there were no other physical abnormalities. Serum urea was $3.5 \mathrm{mmol} / 1(21 \mathrm{mg} / 100 \mathrm{ml})$, electrolytes normal, and creatinine clearance $79 \mathrm{ml} / \mathrm{min}$. Cold agglutinins were present in a titre of $1 / 4$ at $4^{\circ} \mathrm{C}$ and urinary protein excretion less than $100 \mathrm{mg}$ in 24 hours. A chest $x$-ray film showed interstitial fibrosis, and pulmonary function tests showed diminished diffusing capacity. The results of other extensive investigations were normal.

She was initially treated with azathioprine, $100 \mathrm{mg}$ twice daily, and topical corticosteroids and emulsifying ointment. After two weeks she developed anorexia and vomiting. On her second admission to hospital her blood pressure was $240 / 120$, while fundoscopy showed exudates and haemorrhages. She rapidly became oliguric and her creatinine clearance was found to be $4 \mathrm{ml} / \mathrm{min}$. Renal biopsy showed appreciable endothelial proliferation of the arterioles with narrowing of the lumena.

She was established on intermittent haemodialysis twice weekly, and eventually her hypertension was successfully controlled with oxprenolol, $240 \mathrm{mg}$; diazoxide, $200 \mathrm{mg}$; and tolbutamide, $1 \mathrm{~g}$ daily. Azathioprine was discontinued because of leucopenia and prednisolone $5 \mathrm{mg}$ daily maintained. Over 13 months she has developed deep pigmentation and hirsutism (attributed to diazoxide therapy), but she has been generally well, and increasingly active. Her scleroderma has become much less prominent, while repeated examination and investigations have shown no obvious evolving disease of the respiratory or gastrointestinal systems.

\section{Discussion}

The cause of acute renal failure in systemic sclerosis remains unexplained, and there is no evidence that any treatment will halt the progression of renal damage once it has begun. The survival of this patient would seem to be attributable to the early and adequate
Hypocomplementaemia and the presence of $\mathrm{C} 3$ activator (C3 nephritic factor) have been described in the following syndromes: mesangiocapillary nephritis ${ }^{12}$; partial lipodystrophy and recurrent infections ${ }^{3}$; and partial lipodystrophy in combination with mesangiocapillary nephritis. ${ }^{4}$ Hypocomplementaemia induced by $\mathrm{C} 3$ activation has not been described in healthy persons, and we describe such a case here.

\section{Case report}

A 36-year-old woman was seen in February 1974, complaining of pain and stiffness in her thumbs, though these were neither red nor swollen and they moved easily. Her symptoms had started with tonsillitis in December 1972; One week later she had developed a swollen and red right Achilles tendon, followed by migrating pains and stiffness in different joints. She had improved after treatment with salicylates and oxyphenbutazone, but had since then occasionally suffered from arthralgia in her fingers. During the acute illness repeated examinations had shown neither haematuria nor proteinuria; the sedimentation rate (1 hour) was less than $10 \mathrm{~mm}$, and no rise in antistreptolysin $\mathrm{O}$ titre had been detected.

Investigations showed ESR $4 \mathrm{~mm} ; \mathrm{Hb} 12.7 \mathrm{~g} / \mathrm{dl}$, white blood coun $5.7 \times 10^{9} / 1\left(5700 / \mathrm{mm}^{3}\right)$; serum albumin $43 \mathrm{~g} / 1$, urea $1.7 \mathrm{mmol} / 1(10 \mathrm{mg}$ $100 \mathrm{ml}$ ), creatinine clearence $91 \mathrm{ml}$ per min. Urine deposit normal and no proteinuria. Tests for antinuclear factor were negative and antistreptolysin $O$ titre normal. Several blood samples during 1974 showed the presence of very low $\mathrm{C} 3(3.5 \mathrm{mg} / 100 \mathrm{ml})$ and low total hemolytic complement $\left(\mathrm{CH}_{50}\right.$ less than 25 units per $\mathrm{ml}$ ). $\mathrm{C} 3$ nephritic factor was present, as indicated by $\mathrm{C} 3$ breakdown in normal serum in vitro. The levels of Clq, Cls, C4, C3b inactivator (KAF), and properdin were all normal.

\section{Discussion}

Low $\mathrm{C} 3$ concentration induced by $\mathrm{C} 3$ activator was initially found in two-thirds of patients with mesangiocapillary nephritis. The role of hypocomplementaemia in this form of nephritis is obscure, since there is a poor correlation between the activity of glomerular disease and serum complement concentration. ${ }^{5}$ This type of hypocomplementaemia is, however, regarded as a predisposing factor in nephritis. Later C3 activation was described in a woman with partial lipodystrophy and increased susceptibility to infections but with normal renal function. ${ }^{3}$ Our patient with low concentration of $\mathrm{C} 3$ and $\mathrm{C} 3$ activator 